\title{
Effects of vitamin D supplements in patients with chronic hepatitis C: a randomized, multi-center, open label study
}

Jae Yoon Jeong ${ }^{1}$, Dae Won Jun², Sol Ji Park³, Joo Hyun Sohn ${ }^{1}$, Sang Gyune Kim ${ }^{4}$, Se Whan Lee Soung Won Jeong ${ }^{6}$, Moon Young Kim7, Won Kim ${ }^{8}$, Jae-Jun Shim ${ }^{9}$, Hyoung Su Kim ${ }^{10}$, Ki Tae Suk ${ }^{11}$, and Sang Bong $\mathrm{Ahn}^{12}$

\begin{abstract}
${ }^{1}$ Department of Internal Medicine, Hanyang University Guri Hospital, Guri; ${ }^{2}$ Department of Internal Medicine, Hanyang University Hospital, Seoul; ${ }^{3}$ Department of Clinical Pharmacology, Sungkyunkwan University, Seoul; ${ }^{4}$ Department of Internal Medicine, Soonchunhyang University Bucheon Hospital, Bucheon; ${ }^{5}$ Department of Internal Medicine, Soonchunhyang University Cheonan Hospital, Cheonan; ${ }^{6}$ Department of Internal Medicine, Soonchunhyang University Seoul Hospital, Seoul; ${ }^{7}$ Department of Internal Medicine, Yonsei University Wonju Severance Christian Hospital, Wonju; ${ }^{8}$ Department of Internal Medicine, Seoul Metropolitan Government Seoul National University Boramae Medical Center, Seoul; ' ${ }^{2}$ Department of Internal Medicine, Kyung Hee University School of Medicine, Seoul; ${ }^{10}$ Department of Internal Medicine, Hallym University Kangdong Sacred Heart Hospital, Seoul; ${ }^{11}$ Department of Internal Medicine, Hallym University Chuncheon Sacred Heart Hospital, Chuncheon; ${ }^{12}$ Department of Internal Medicine, Eulji University School of Medicine, Seoul, Korea
\end{abstract}

Received: July 20, 2018 Revised : October 29, 2018 Accepted: November 5, 2018
Background/Aims: We aimed to assess the role of vitamin D supplementation in the response to pegylated interferon- $\alpha$ (PEG-IFN- $\alpha$ ) plus ribavirin (RBV) treatment in patients with chronic hepatitis $\mathrm{C}$ (CHC).

Methods: Our study was a multi-center, randomized controlled trial in 11 hospitals. CHC patients were randomly assigned (1:1) to two groups namely, PEGIFN- $\alpha$ plus RBV (control group) or PEG-IFN- $\alpha$ plus RBV + vitamin D (80o IU daily) (vitamin $\mathrm{D}$ group). The primary end-point was the rate of sustained virologic response (SVR).

Results: One hundred forty eight CHC patients were randomly assigned to two groups. Seventy-one patients received the PEG-IFN- $\alpha$ plus RBV and 77 patients received the PEG-IFN- $\alpha$ plus RBV + vitamin D. A total of 105 patients completed the study (control group, 47 vs. vitamin D group, 58). Baseline characteristics were mostly similar in both the groups. There was a modest but non-significant increase in SVR in the vitamin D group compared to the control group with the intention to treat analysis $(64.0 \%$ vs. $49.3 \%, p=0.071)$ as well as in the per protocol analysis (control group vs. vitamin D group: $74.5 \%$ vs. $84.5 \%, p=0.202$ ). Fifty-two patients $(73.2 \%)$ in the control group and 63 patients $(81.8 \%)$ in the vitamin D group experienced at least one adverse event. The drop-out rate due to adverse effects was not different between both groups (control group vs. vitamin D group: $19.7 \%$ vs. $10.4 \%, p=0.111$ ).

Conclusions: Vitamin D supplement did not increase SVR in treatment naïve patients with CHC irrespective of genotype.

Keywords: Chronic hepatitis C; Vitamin D; Sustained virologic response

\section{Correspondence to Dae Won Jun, M.D.}

Department of Internal Medicine, Hanyang University College of Medicine, 222-1

Wangsimni-ro, Seongdong-gu, Seoul 04763 , Korea.

Tel: +82-2-2290-8338, Fax: +82-2-972-0068, E-mail: noshin@hanyang.ac.kr 


\section{INTRODUCTION}

Vitamin D has a variety of functions in addition to calcium and bone metabolism, such as insulin resistance, metabolic diseases, immune function and various functions with regard to muscles. Vitamin D is a seco-steroid hormone involved in innate immunity, cell differentiation, inflammation and fibrogenesis besides regulation of bones and calcium/phosphorus homeostasis [1]. Vitamin $\mathrm{D}$ deficiency is known to increase the risk of cancer, autoimmune diseases, cardiovascular diseases and infectious diseases [2-5].

The institute of medicine and the World Health Organization define the normal range of vitamin $\mathrm{D}$ as above $20 \mathrm{ng} / \mathrm{mL}$ [6]. Prevalence of vitamin D insufficiency is relatively common, and is about $52 \%$ to $72 \%$ in the average risk group [7-9]. The prevalence of vitamin D insufficiency in the general population was $41.6 \%$ in the United States [10], 40.4\% in Europe [11], and 40.8\% in Japan [12]. Known prevalence of vitamin D insufficiency in chronic liver diseases is about $64 \%$ to $94 \%$ [13]. Previous meta-analysis for patients with chronic hepatitis $\mathrm{C}$ (CHC) reported that the prevalence of vitamin D insufficiency was about $80 \%$, much higher than that in the general population [14]. In CHC, the lower the levels of vitamin $\mathrm{D}$, the greater is the degree of fibrosis and inflammation in the liver, and the poorer is the response to interferon-based treatment $[14,15]$.

Although there is clear association between chronic liver disease and vitamin $\mathrm{D}$ insufficiency, it is not clear about the mechanism of serum vitamin $\mathrm{D}$ insufficiency in chronic liver disease. At the same time, there is another controversy as to whether low serum vitamin D causes a decrease in immune function resulting in high prevalence of viral hepatitis or chronic liver diseases lead to vitamin $\mathrm{D}$ metabolic disorders in liver to induce vitamin D deficiency [16-18].

For these reasons, many studies have examined the effects of vitamin D supplements on sustained virologic response (SVR) in pegylated interferon- $\alpha$ (PEG-IFN- $\alpha$ ) plus ribavirin (RBV) therapy in patients with $\mathrm{CHC}$ [1923]. Several studies have been reported on the association of vitamin D supplementation with treatment response in patients with $\mathrm{CHC}$ [19-21]. However, a possible role of vitamin D supplementation in PEG-IFN- $\alpha$ plus RBV therapy is still debatable [24]. We investigated to assess the role of vitamin D supplementation in the response to PEG-IFN- $\alpha$ plus RBV treatment in naïve patients with $\mathrm{CHC}$.

\section{METHODS}

\section{Patients}

Our study was a randomized, multi-center, open-label trial between September 2011 and April 2015 in 11 hospitals in the Republic of Korea. Patients with CHC were screened in this study. A diagnosis of $\mathrm{CHC}$ was established according to the guidelines of the Korea Association for the Study of the Liver (KASL) [25]. The inclusion criteria were age 20 to 75 years, patients found positive in hepatitis $\mathrm{C}$ virus-ribonucleic acid polymerase chain reaction (HCV-RNA PCR) screening, normal serum calcium level before treatment, and HCV genotypes 1, 2, and 3. Exclusion criteria were hepatocelluar carcinoma (HCC) at enrollment or past history of HCC within last 1 year, decompensated cirrhosis (Child-Pugh class B or C), absolute neutrophil count $<1,000 / \mathrm{mm}^{3}$ or platelet count $<70,000 / \mathrm{mm}^{3}$, serum creatinine level above 1.5 times to upper normal limit, a present or past history of severe psychiatric diseases, parathyroid disease, uncontrolled thyroid disease, co-infection with other hepatitis virus or human immunodeficiency virus, history of malignant diseases besides HCC within last 2 years, patients who were considered unfit to perform clinical trial, and pregnancy. This study protocol conformed to the ethical guidelines of the 1975 Declaration of Helsinki and was approved by the ethics committee of each hospital (for example, IRB No. of Hanyang University Hospital: 2011-05-001) and is registered at ClinicalTrial.gov (NCTo1439776).

After applying inclusion and exclusion criteria, they were stratified according to HCV viral load $(\geq 600,000$ $\mathrm{IU} / \mathrm{mL}$ vs. $<600,000 \mathrm{IU} / \mathrm{mL}$ ) and genotypes (1 vs. 2 and 3 ), and randomly assigned (1:1) to two groups namely, PEGIFN- $\alpha$ plus RBV (control group) and PEG-IFN- $\alpha$ plus $\mathrm{RBV}+$ vitamin $\mathrm{D}$ (vitamin D group). All the included patients had provided written informed consent.

\section{Treatment strategy}

Treatment of CHC was based on the guidelines of the KASL [25]. Control group received once a week PEG-IFN 


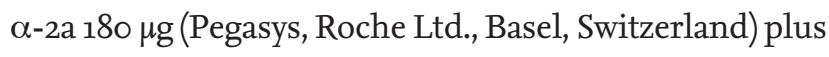
oral ribavirin $1,000 \mathrm{mg}$ (body weight $<75 \mathrm{~kg}$ ) or 1,200 $\mathrm{mg}$ (body weight $\geq 75 \mathrm{~kg}$ ) daily in genotype 1 , or oral ribavirin $800 \mathrm{mg}$ daily in genotype 2 and 3 . Vitamin $\mathrm{D}$ group received identical therapy with oral vitamin D $800 \mathrm{IU}$ (GNC Korea, Seoul, Korea) daily. The planned duration of treatment was 48 weeks for genotype 1 and 24 weeks for genotypes 2 and 3 .

When the absolute neutrophil count fell below 750/ $\mathrm{mm}^{3}$ or platelet count fell below 50,000/ $\mathrm{mm}^{3}$, the PEGINF- $\alpha$ dose was decreased, and when the absolute neutrophil count fell below $500 / \mathrm{mm}^{3}$ or platelet count fell below $25,000 / \mathrm{mm}^{3}$, the treatment was temporarily stopped until absolute neutrophil count became more than $1,000 / \mathrm{mm}^{3}$ or platelet count became more than $75,000 / \mathrm{mm}^{3}$. When resuming PEG-INF- $\alpha$ administration, a starting dose of $90 \mu \mathrm{g}$ was used and neutrophil count or platelet count was closely monitored. The ribavirin dose was adjusted considering the following. (1) When the hemoglobin level decreased below $10 \mathrm{~g} / \mathrm{dL}$, the ribavirin dose was gradually decreased. When the hemoglobin level decreased below $8 \mathrm{~g} / \mathrm{dL}$, the ribavirin administration was stopped. (2) Patients who discontinued ribavirin therapy continued to receive PEG-INF- $\alpha$ monotherapy for the remaining treatment period. Once the anemia was restored, the ribavirin was re-administered according to the clinician's decision.

\section{Monitoring and follow-up}

Patients visited the clinic at baseline, at every 4 weeks for the first 12 weeks of treatment and then every 3 months until the completion of treatment. All patients followed up at 24 weeks after the completion of treatment. At each visit, a physical examination was conducted, adverse drug events were recorded, and compliance with medication intake was assessed by pill counts. Body mass index, vital signs, and blood tests such as complete blood count, prothrombin time (international normalized ratio), alanine aminotransferase, aspartate aminotransferase, total bilirubin, albumin, creatinine, calcium, phosphate, glucose, lipid profiles (total cholesterol, triglycerides, high density lipoprotein cholesterol, low density lipoprotein cholesterol), fasting insulin and 25 -hydroxy $(25[\mathrm{OH}])$ vitamin $\mathrm{D}_{3}$ were performed at baseline. Vitamin D deficiency was defined as $25(\mathrm{OH})$ vitamin $\mathrm{D}_{3}<10 \mathrm{ng} / \mathrm{mL}$ and vitamin $\mathrm{D}$ insufficiency as
$25(\mathrm{OH})$ vitamin $\mathrm{D}_{3}$ of $\geq 10$ to $<20 \mathrm{ng} / \mathrm{mL}$. Patients were screened for hepatocellular carcinoma every 6 months by $\alpha$-fetoprotein assay and ultrasonography.

Serum HCV RNA quantification was measured using real-time polymerase chain reaction. HCV RNA was performed at baseline and after 4, 12, and 48 weeks of treatment for genotype 1 and at baseline and after 4, 12, and 24 weeks of treatment for genotype 2 and 3. Rapid virological response, early virological response and end of treatment response were defined as the undetectable HCV RNA at 4 weeks after initiation of treatment, as the undetectable HCV RNA or reduction by more than $2 \log _{10}$ copies/mL at 12 weeks of treatment, and as the undetectable HCV RNA at the end of treatment, respectively. SVR was defined as the undetectable HCV RNA at 24 weeks after the completion of treatment and was considered as cure.

\section{Endpoints and safety evaluation}

The primary endpoint was the rate of SVR. Secondary endpoints were risk factors for SVR. The responders were defined as patients who achieved SVR, and the non-responders were defined as those who did not achieve SVR. Safety assessments included adverse events, laboratory findings and vital signs. Adverse events were classified as mild, moderate or severe, and as definitely related, probably related, possibly related, probably not related or definitely not related.

\section{Statistical analysis}

The level of significance for the primary endpoint was $2.5 \%$ on the single side because this study is a superiority trial. The 91 subjects in each group provided a power of $80 \%$ for identifying SVR of $77 \%$ in PEG-IFN- $\alpha$ / RBV treatment and a difference of $15 \%$ in SVR between control group and vitamin D group. Assuming a 20\% drop-out rate, a sample size of 114 subjects in each group was needed. However, this study was stopped early because of the difficulty in recruiting patients with the advent of new oral directly acting agents for treatment of CHC.

Categorical variables are given as frequencies (\%) and continuous variables are given as mean values with standard deviations. Clinical and laboratory factors that affected SVR were analyzed by using chi-square test or the Fisher exact test. Subsequently, multivariate logistic 
Table 1. Baseline clinical characteristics of patients

\begin{tabular}{|c|c|c|c|}
\hline Characteristic & Control group $(\mathrm{n}=71)$ & Vitamin D group $(\mathrm{n}=77)$ & $p$ value \\
\hline Age, yr & $51.6 \pm 9.9$ & $51.5 \pm 9.4$ & 0.977 \\
\hline Male sex & $30(42.3)$ & $42(54 \cdot 5)$ & 0.135 \\
\hline Genotype 1 & $28(39.4)$ & $25(32.5)$ & 0.377 \\
\hline HCV PCR, $10^{6} \mathrm{IU} / \mathrm{mL}$ & $4.399 \pm 7.758$ & $4.221 \pm 7.842$ & 0.890 \\
\hline$>600,000 \mathrm{IU} / \mathrm{mL}$ & $43(60.6)$ & $41(53.2)$ & 0.369 \\
\hline Cirrhosis & $5(7 \cdot 0)$ & $6(7.8)$ & 0.862 \\
\hline Body mass index, $\mathrm{kg} / \mathrm{m}^{2}$ & $24.2 \pm 3 \cdot 5$ & $24.7 \pm 3 \cdot 3$ & 0.347 \\
\hline Waist circumference, $\mathrm{cm}$ & $85.8 \pm 10.7$ & $87 \cdot 3 \pm 9 \cdot 3$ & 0.343 \\
\hline Diabetes mellitus & $11(15 \cdot 5)$ & $9(11.7)$ & 0.499 \\
\hline Hypertension & $20(28.2)$ & $16(20.8)$ & 0.295 \\
\hline Hyperlipidemia & $3(4 \cdot 2)$ & $2(2.6)$ & 0.671 \\
\hline Drinker, never/ex-/current & $36(50.7) / 6(8.5) / 29(40.8)$ & $34(44.2) / 8(11.7) / 34(44.2)$ & 0.666 \\
\hline Smoker, never/ex-/current & $39(54.9) / 8(11.3) / 24(33.8)$ & $39(54.9) / 11(14.3) / 27(35.1)$ & 0.816 \\
\hline Sun exposure, hr/day & $2.7 \pm 2.3$ & $2.0 \pm 1.5$ & 0.024 \\
\hline Platelet count, $10^{3} / \mu \mathrm{L}$ & $190 \pm 62$ & $182 \pm 60$ & 0.443 \\
\hline Prothrombin time, INR & $1.00 \pm 0.75$ & $0.98 \pm 0.14$ & 0.207 \\
\hline $\mathrm{AST}, \mathrm{U} / \mathrm{L}$ & $77 \pm 55$ & $80 \pm 83$ & 0.794 \\
\hline ALT, U/L & $80 \pm 75$ & $98 \pm 141$ & 0.334 \\
\hline Total bilirubin, mg/dL & $0.7 \pm 0.3$ & $0.7 \pm 0.4$ & 0.431 \\
\hline Albumin, g/dL & $4 \cdot 3 \pm 0.4$ & $4.3 \pm 0.3$ & 0.832 \\
\hline Glucose, mg/dL & $108 \pm 49$ & $110 \pm 34$ & 0.806 \\
\hline HOMA-IR & $7 \cdot 48 \pm 12.7$ & $4.64 \pm 5.83$ & 0.121 \\
\hline Calcium, mg/dL & $9.2 \pm 0.4$ & $9.2 \pm 0.4$ & 0.746 \\
\hline Phosphorus, mg/dL & $3.7 \pm 0.6$ & $3.7 \pm 0.7$ & 0.820 \\
\hline Creatinine, mg/dL & $0.8 \pm 0.2$ & $0.8 \pm 0.2$ & 0.613 \\
\hline Cholesterol, mg/dL & $170 \pm 36$ & $172 \pm 30$ & 0.692 \\
\hline Triglycerides, mg/dL & $126 \pm 73$ & $116 \pm 63$ & 0.444 \\
\hline $\mathrm{HDL}, \mathrm{mg} / \mathrm{dL}$ & $48 \pm 15$ & $51 \pm 16$ & 0.312 \\
\hline $\mathrm{LDL}, \mathrm{mg} / \mathrm{dL}$ & $101 \pm 29$ & $102 \pm 29$ & 0.729 \\
\hline${ }_{25}(\mathrm{OH}) \operatorname{vitamin} \mathrm{D}_{3}, \mathrm{ng} / \mathrm{mL}^{\mathrm{a}}$ & $15.6 \pm 8.7$ & $15 \cdot 5 \pm 8.1$ & 0.809 \\
\hline$<10$ & $18(26.9)$ & $19(25 \cdot 7)$ & 0.965 \\
\hline $10-20$ & $32(47.8)$ & $37(36.2)$ & \\
\hline$\geq 20$ & $17(25.4)$ & $18(24 \cdot 3)$ & \\
\hline
\end{tabular}

Values are presented as mean $\pm \mathrm{SD}$ or number (\%).

HCV PCR, hepatitis C virus polymerase chain reaction; INR, international normalized ratio; AST, aspartate aminotransferase; ALT, alanine aminotransferase; HOMA-IR, homeostasis model assessment of insulin resistance index; HDL, high density lipoprotein; LDL, low density lipoprotein; 25(OH), 25-hydroxy.

${ }^{a}$ Number of control group $=67$, number of vitamin D group $=74$.

regression analysis was performed to assess the factors that showed significant associations with SVR in the univariate analyses. Statistical significance in 2-sided tests was defined as $p<0.05$. All statistical analyses were performed by using the SPSS version 18.0 for Windows (SPSS Inc., Chicago, IL, USA). 


\section{RESULTS}

\section{Baseline characteristics}

Seventy-one patients received the PEG-IFN- $\alpha$ plus RBV

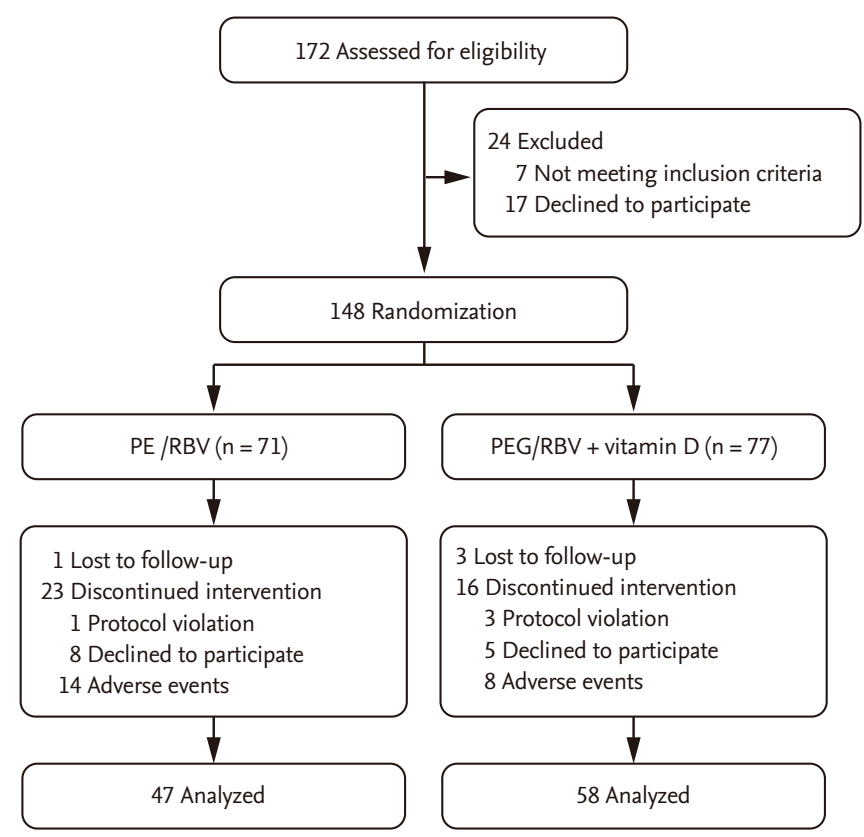

Figure 1. Flow diagram of enrolled patients. PEG, pegylated; RBV, ribavirin.

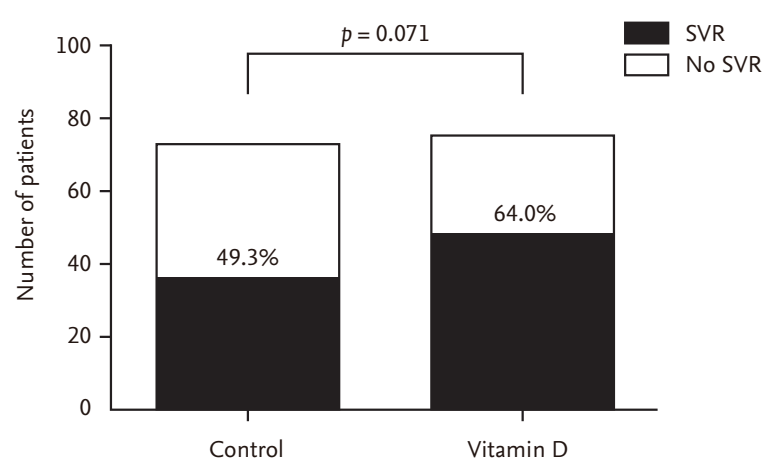

Figure 2. Sustained virologic response (SVR) between control group and vitamin $\mathrm{D}$ group in intention to treat analysis. and 77 patients received the PEG-IFN- $\alpha$ plus RBV + vitamin D. Twenty-four patients (33.8\%) in the control group and 19 patients (24.7\%) in the vitamin D group, dropped out during the treatment period (Fig. 1). There was no significant difference in drop-out rates between the two groups $(p=0.222)$. Baseline characteristics were mostly similar in both the groups, as shown in Table 1.

\section{Viral response rate}

Vitamin D group (48/75, 64.0\%) showed non-significantly higher the rates of SVR as compared to the control group $(36 / 73,49.3 \%)(p=0.071)$ (Fig. 2$)$ in the intention to treat analysis. The subgroup analysis according to genotype yielded similar results for the rates of SVR in both the groups (for genotype 1, control group: $26.7 \%$ vs. vitamin D group: $43.5 \%, p=0.200$; and for genotype 2 and 3 , control group: $65.1 \%$ vs. vitamin D group: $73.1 \%, p$ $=0.402)$. SVR was $74.5 \%$ (35/47) in the control group and $84.5 \%$ (49/58) in the vitamin D group, but the difference between both the groups was not statistically significant $(p=0.202)$ using per protocol (PP) analysis (Table 2).

\section{Factors associated with SVR}

Of the 105 patients in the PP analysis, 21 patients (20.0\%) failed to achieve SVR. In univariate analysis, the failure to achieve SVR was significantly associated with genotype 1, high viral load (>600,000 IU/mL), waist circumference and total bilirubin (Table 3). In multivariate analysis, genotype 1 , high viral load (> 600,000 IU/mL) and waist circumference were independent predictors of the failure to achieve SVR (Table 3). Baseline serum vitamin D levels and additional supplementation of vitamin D were not associated with viral response.

Viral response rate according to serum vitamin $D$ level. Baseline serum vitamin D levels were $15.6 \mathrm{ng} / \mathrm{dL}$ in the control group and $15.5 \mathrm{ng} / \mathrm{dL}$ in the vitamin $\mathrm{D}$ group $(p=$ $0.809)$. Vitamin D deficiency was observed in 18 patients $(26.9 \%)$ in the control group and 19 patients $(25.7 \%)$ in

Table 2. Sustained virologic response between control group and vitamin $D$ group in per protocol analysis

\begin{tabular}{lccc}
\hline Variable & Control group $(\mathrm{n}=47)$ & Vitamin D group $(\mathrm{n}=58)$ & $p$ value \\
\hline All & $35 / 47(74.5)$ & $49 / 58(84.5)$ & 0.202 \\
Genotype 1 & $7 / 16(43.8)$ & $11 / 17(64.7)$ & 0.227 \\
Genotype 2/3 & $28 / 31(90.3)$ & $38 / 41(92.7)$ & 0.720 \\
\hline
\end{tabular}

Values are presented as number (\%). 
Table 3. Independent risk factors associated with no sustained virologic response

\begin{tabular}{|c|c|c|c|c|c|}
\hline Factor before treatment & $\begin{array}{l}\text { Responder } \\
(\mathrm{n}=84)\end{array}$ & $\begin{array}{l}\text { Non-responder } \\
\qquad(\mathrm{n}=21)\end{array}$ & $\begin{array}{c}\text { Univariate } \\
\text { analysis } p \text { value }\end{array}$ & OR $(95 \% \mathrm{CI})^{\mathrm{a}}$ & $\begin{array}{c}\text { Multivariate } \\
\text { analysis p value }\end{array}$ \\
\hline Age, yr & $50.3 \pm 9.4$ & $52.7 \pm 9.1$ & 0.286 & & \\
\hline Sex, male & $39(46.4)$ & $10(47.6)$ & 0.922 & & \\
\hline Genotype 1 & $18(21.4)$ & $15(71.4)$ & $<0.001$ & $8.72(2.27-33.54)$ & 0.002 \\
\hline $\mathrm{BMI}, \mathrm{kg} / \mathrm{m}^{2}$ & $24 \cdot 3 \pm 3 \cdot 0$ & $26.0 \pm 4.9$ & 0.050 & & \\
\hline Waist circumference, $\mathrm{cm}$ & $85.6 \pm 9.1$ & $90.8 \pm 13.1$ & 0.036 & $1.09(1.02-1.18)$ & 0.016 \\
\hline Diabetes mellitus & $8(9.5)$ & $5(23.8)$ & 0.075 & & \\
\hline Sun exposure, hr/day & $2.5 \pm 2.1$ & $2.8 \pm 2.5$ & 0.487 & & \\
\hline Total bilirubin, mg/dL & $0.6 \pm 0.3$ & $0.8 \pm 0.4$ & 0.013 & & \\
\hline Albumin, g/dL & $4.4 \pm 0.3$ & $4.2 \pm 0.3$ & 0.087 & & \\
\hline${ }_{25}(\mathrm{OH})$ vitamin $\mathrm{D}_{3}, \mathrm{ng} / \mathrm{mL}^{\mathrm{a}}$ & $15 \cdot 9 \pm 7 \cdot 7$ & $15.7 \pm 10.4$ & 0.922 & & \\
\hline$<10$ & $16(20.3)$ & $5(26.3)$ & 0.332 & & \\
\hline $10-20$ & $33(53.2)$ & $11(57.9)$ & & & \\
\hline$\geq 20$ & $17(26.6)$ & $3(15.8)$ & & & \\
\hline Vitamin D supplementation & $49(58.3)$ & $9(42.9)$ & 0.202 & & \\
\hline $\mathrm{AFP}, \mathrm{ng} / \mathrm{mL}$ & $8.3 \pm 14.1$ & $14 \cdot 4 \pm 14 \cdot 7$ & 0.081 & & \\
\hline $\mathrm{HCV}$ PCR > 600,000 IU/mL & $44(53.0)$ & $18(85.7)$ & 0.031 & $6.27(1.18-33.52)$ & 0.031 \\
\hline Cirrhosis & $7(8.3)$ & $3(14 \cdot 3)$ & 0.415 & & \\
\hline
\end{tabular}

Values are presented as mean $\pm \mathrm{SD}$ or number $(\%)$.

OR, odds ratio; CI, confidence interval; BMI, body mass index; AFP, alpha fetoprotein; HCV PCR, hepatitis C virus polymerase chain reaction.

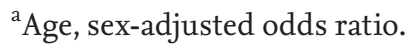

Table 4. Sustained virologic response between control group and vitamin $\mathrm{D}$ group in patients with $25(\mathrm{OH})$ vitamin $\mathrm{D}_{3}<$ $20 \mathrm{ng} / \mathrm{mL}$

\begin{tabular}{lcc}
\hline Variable & $\begin{array}{c}\text { Control group } \\
(\mathrm{n}=27)\end{array}$ & $\begin{array}{c}\text { Vitamin D group } \\
(\mathrm{n}=41)\end{array}$ \\
\hline All & $23 / 27(85.2)$ & $35 / 41(85.4)$ \\
Genotype 1 & $5 / 7(71.4)$ & $7 / 10(70.0)$ \\
Genotype 2/3 & $18 / 20(90.0)$ & $28 / 31(90.3)$ \\
\hline
\end{tabular}

the vitamin D group ( $p=0.965)$. SVR rate did not vary according to baseline serum vitamin D levels $(p=0.161)$. Also, in the subgroup analysis of patients with $25(\mathrm{OH})$ vitamin $\mathrm{D}_{3}<20 \mathrm{ng} / \mathrm{mL}$, there was no difference in SVR rate according to vitamin $\mathrm{D}$ supplementation (all $p$ value $=1.000$ ) (Table 4).

In the vitamin $\mathrm{D}$ group $(\mathrm{n}=58)$, the mean serum vitamin D levels increased from $17.0 \pm 8.8 \mathrm{ng} / \mathrm{mL}$ before treatment to $17.6 \pm 9.0 \mathrm{ng} / \mathrm{mL}$ after treatment, but there was no statistical difference $(p=0.524)$. There were 26 patients (44.8\%) with elevated serum vitamin D levels and $32(55.2 \%)$ with decreased serum vitamin D levels after treatment. SVR rate did not vary according to the change in vitamin D levels (group with decreased serum vitamin D levels vs. group with elevated serum vitamin D levels: $80.8 \%$ vs. $90.6 \%, p=0.446$ ).

\section{Safety}

A total of 115 patients (77.7\%) experienced at least one adverse event, 52 (73.2\%) of them in the control group and $6_{3}(81.8 \%)$ in the vitamin D group. Most adverse events were mild and similar in both the groups. Serious adverse events occurred in 10 patients, but all recovered. The drop-out rate due to adverse effects was not different between both the groups (control group vs. vitamin D group: $19.7 \%$ vs. $10.4 \%, p=0.111$ ). There was no adverse event related to vitamin $\mathrm{D}$ supplements. 


\section{DISCUSSION}

In this study, we evaluated the efficacy and safety of vitamin D supplementation in the response to PEG-IFN- $\alpha$ plus RBV therapy in treatment of naïve patients with CHC. Vitamin D supplement did not significantly increase SVR in PEG-IFN- $\alpha$ treatment of naïve patients with $\mathrm{CHC}$ regardless of genotype. Also, baseline serum vitamin $\mathrm{D}$ levels were not associated with treatment response.

It is well known that serum vitamin D levels are decreased in chronic liver diseases [26]. In this study, 75.2\% of enrolled patients with CHC had vitamin D insufficiency and deficiency. In addition, the lower serum vitamin D levels in patients with $\mathrm{CHC}$ showed a more advanced degree of fibrosis and a lower treatment response to IFN-based therapy [14,15]. Therefore, there have been many studies on whether vitamin D supplementation positively affects treatment response (SVR) in patients with CHC who have been treated with PEGIFN- $\alpha$ [19-22].

It is still unclear how vitamin D supplementation has a synergistic effect on the improvement of the viral response. Several mechanisms have been suggested for this effect. In CHC, various proinflammatory cytokines such as TNF- $\alpha$ and chemokine CXCL1o cause intrahepatic inflammation and disease progression [27,28]. Vitamin D can have an antiinflammatory effect on these cytokines. Vitamin D also has antifibrotic effects. Abramovitch et al. [29] showed that in vitro and in vivo 1,25(OH $)_{2} \mathrm{D}$ inhibits fibrosis by inhibiting the proliferation and profibrosis action of hepatic stellate cells. Recently, Komolmit et al. [30] showed that vitamin D supplementation in patients with $\mathrm{CHC}$ improved the serum markers such as TGF- $\beta$, TIMP-1, MMP2, and MMP2, associated with hepatic fibrogenesis. This suggests that vitamin $\mathrm{D}$ plays an important role in the reversal of hepatic fibrosis [30]. In addition, in vitro, vitamin $\mathrm{D}$ enhances the expression of IFN- $\beta$ and the induction of IFN-stimulated genes resulting in a synergic effect on the antiviral activity of IFN [31]. Vitamin D also affects the improvement of insulin resistance, which affects SVR [32].

This study is a randomized, multi-center, open-label trial. In this study, serum vitamin D levels did not increase viral response in patients with $\mathrm{CHC}$. There were some reports whether vitamin D supplement can aug- ment viral response in patients with CHC [19-23]. Although there have been some studies whether vitamin $\mathrm{D}$ use can be helpful in the treatment of CHC infection [19-21], the results were controversial. Abu-Mouch et al. [20] reported in a study of 40 patients with HCV genotype 1 that, vitamin D 1,000 IU/day supplementation resulted in a $40 \%$ increase in SVR rates compared to standard therapy. Same group also published that adding vitamin D to conventional PEG-IFN treatment for patients with HCV genotype 2 and 3 increased viral response (control group vs. vitamin D group: 95\% vs. $77 \%$, $p<0.001)[21]$. However, these reports were not support by following studies. Yokoyama et al. [22] added vitamin D (1,000 IU/day) to PEG-IFN/RBV therapy in patients with HCV genotype $1 \mathrm{~b}$; however, SVR rates were not different in the vitamin D and control groups (64.3\% vs $50 \%, p=0.19)$. Esmat et al. [23] also tried to show the possible role of vitamin $\mathrm{D}$ supplementation in patients with HCV genotype 4. However, the study by Esmat et al. [23] showed that vitamin D supplementation did not increase SVR in patients with HCV genotype 4. Therefore, there is still controversy whether vitamin D supplement can increase viral response. Recently, meta-analysis reported that vitamin D supplementation improved SVR in patients with CHC [33]. However, as noted in this meta-analysis, it is difficult to confirm this efficacy of vitamin D supplementation, because most studies have small sample sizes, low methodological quality and heterogenicity [33]. Another reason of this difference seems to result from higher SVR in Asia, especially in East Asia than in Western countries, because SVR rate of IFNbased treatment was quite different according to geographic region [33].

There have been many reports that serum vitamin D levels were associated with treatment success before starting the treatment $[14,15]$, but there is a lack of research into whether serum vitamin D levels increase after successful treatment. Lange et al. [34] pointed out that HCV infection itself affects vitamin D metabolism and synthesis. In patients who achieved SVR, serum vitamin D levels were slightly elevated (pretreatment vs. posttreatment: $16.2 \mathrm{ng} / \mathrm{mL}$ vs. $18.2 \mathrm{ng} / \mathrm{mL}$ ) and incidence of vitamin D deficiency (< $10 \mathrm{ng} / \mathrm{mL}$ ) was lower (pretreatment vs. posttreatment: $33 \%$ vs. $26 \%$ ) in that study, but it was not statistically significant. At the same time, seasonal and dietary factors were also not considered. A 
recent cohort study of 218 patients reported that serum vitamin $\mathrm{D}$ levels remained unchanged during direct-acting antiviral therapy (pre-treatment vs. post-treatment: $25.3 \pm 15.9$ vs. $26.4 \pm 12.5, p=0.10$ ) [35]. In addition, this cohort study did not consider important variables such as seasonal factors [35].

Serum vitamin D levels are generally more affected by sun exposure than food and supplements [1]. However, these are now important sources, especially in modern urban people who live indoors [1]. In several studies, vitamin D supplementation increased serum vitamin D levels [19-23]. In this study, serum vitamin D levels increased after supplementation but were not statistically significant. Therefore, it is thought that serum vitamin $\mathrm{D}$ level is influenced not only by supplements but also by various factors. In addition, this seems to be partially due to the seasonal differences caused by 33 to 38 degrees latitude of Korea. In a recent study, although vitamin D intake was reduced, vitamin D levels were increased by weight loss in patients with nonalcoholic fatty liver disease. This suggests that weight loss has a more influence on serum vitamin D levels than vitamin D intake [36].

Taken together these facts, the causal relationship of lack of vitamin D level in chronic liver disease is still unclear. The results of this study might suggest that insight into the causal relationship of lack of vitamin D concentration in patients with CHC. In this study, additional supplementation of vitamin D in patients with CHC did not increase SVR rate, nor was there any association with baseline vitamin D levels and SVR rate. Also, vitamin D levels did not increase after successful hepatitis $\mathrm{C}$ treatment. These results suggest that the reduction of vitamin D level in CHC is more likely to be caused by other factors such as bad life style rather than chronic liver disease itself. Therefore, it may be more important to find other risk factors that may lower vitamin D levels than vitamin D supplementation for the correction of low vitamin D levels in patients with chronic liver disease.

This study had several limitations. First, this prospective and randomized study was open label but not placebo controlled. Therefore, the patients knew whether vitamin D was administered or not. Second, during the study period, this study was early terminated by the advent of direct acting antivirals and only $64.9 \%$ of the target patients were registered. Therefore, a clear asso- ciation between vitamin D supplement and SVR has not been elucidated. Third, the degree of ultraviolet exposure and weight changes that could affect serum vitamin $\mathrm{D}$ levels were not assessed. Finally, there is no data on hepatic fibrosis and IL-28B polymorphism, important factors affecting SVR in PEG-IFN- $\alpha$ plus RBV therapy.

In conclusion, vitamin $\mathrm{D}$ supplementation did not increase SVR in PEG-IFN- $\alpha$ plus RBV treatment of naïve patients with $\mathrm{CHC}$ regardless of genotype. At the same time, serum vitamin D levels were not associated with treatment response. Therefore, larger, randomized, placebo-controlled trial is needed to assess a robust association between vitamin D supplement and SVR in patients with CHC.

\section{KEY MESSAGE}

1. Vitamin D supplementation did not increase sustained virologic response in pegylated interferon- $\alpha$ and ribavirin treatment of naïve patients with chronic viral hepatitis $\mathrm{C}$ regardless of genotype.

2. Also, serum vitamin D levels were not associated with treatment response.

\section{Conflict of interest}

No potential conflict of interest relevant to this article was reported.

\section{REFERENCES}

1. Rahman AH, Branch AD. Vitamin D for your patients with chronic hepatitis C? J Hepatol 2013;58:184-189.

2. Holick MF. Vitamin D: importance in the prevention of cancers, type 1 diabetes, heart disease, and osteoporosis. Am J Clin Nutr 2004;79:362-371.

3. Giovannucci E, Liu Y, Rimm EB, et al. Prospective study of predictors of vitamin D status and cancer incidence and mortality in men. J Natl Cancer Inst 2006;98:451-459.

4. Dobnig H, Pilz S, Scharnagl H, et al. Independent association of low serum 25-hydroxyvitamin $d$ and 1,25-dihydroxyvitamin d levels with all-cause and cardiovascular mortality. Arch Intern Med 2008;168:1340-1349.

5. Liu PT, Stenger S, Li H, et al. Toll-like receptor triggering 
of a vitamin D-mediated human antimicrobial response. Science 2006;311:1770-1773.

6. Ross AC. The 2011 report on dietary reference intakes for calcium and vitamin D. Public Health Nutr 2011;14:938939.

7. Holick MF, Siris ES, Binkley N, et al. Prevalence of vitamin D inadequacy among postmenopausal North American women receiving osteoporosis therapy. J Clin Endocrinol Metab 2005;90:3215-3224.

8. Lips P, Hosking D, Lippuner K, et al. The prevalence of vitamin $\mathrm{D}$ inadequacy amongst women with osteoporosis: an international epidemiological investigation. J Intern Med 2006;260:245-254.

9. Orwoll E, Nielson CM, Marshall LM, et al. Vitamin $\mathrm{D}$ deficiency in older men. J Clin Endocrinol Metab 2009;94:1214-1222.

10. Forrest KY, Stuhldreher WL. Prevalence and correlates of vitamin D deficiency in US adults. Nutr Res 2011;31:48-54.

11. Cashman KD, Dowling KG, Skrabakova Z, et al. Vitamin D deficiency in Europe: pandemic? Am J Clin Nutr 2016;103:1033-1044.

12. Akter S, Eguchi M, Kurotani K, et al. Serum 25-hydroxyvitamin D and metabolic syndrome in a Japanese working population: the Furukawa Nutrition and Health Study. Nutrition 2017;36:26-32.

13. Fisher L, Fisher A. Vitamin D and parathyroid hormone in outpatients with noncholestatic chronic liver disease. Clin Gastroenterol Hepatol 2007;5:513-520.

14. Garcia-Alvarez M, Pineda-Tenor D, Jimenez-Sousa MA, Fernandez-Rodriguez A, Guzman-Fulgencio M, Resino S. Relationship of vitamin D status with advanced liver fibrosis and response to hepatitis $\mathrm{C}$ virus therapy: a meta-analysis. Hepatology 2014;60:1541-1550.

15. Petta S, Camma C, Scazzone C, et al. Low vitamin D serum level is related to severe fibrosis and low responsiveness to interferon-based therapy in genotype 1 chronic hepatitis C. Hepatology 2010;51:1158-1167.

16. Ford ES, Ajani UA, McGuire LC, Liu S. Concentrations of serum vitamin $\mathrm{D}$ and the metabolic syndrome among U.S. adults. Diabetes Care 2005;28:1228-1230.

17. Ford ES, Zhao G, Li C, Pearson WS. Serum concentrations of vitamin $\mathrm{D}$ and parathyroid hormone and prevalent metabolic syndrome among adults in the United States. J Diabetes 2009;1:296-303.

18. Lu L, Yu Z, Pan A, et al. Plasma 25-hydroxyvitamin D concentration and metabolic syndrome among mid- dle-aged and elderly Chinese individuals. Diabetes Care 2009;32:1278-1283.

19. Bitetto D, Fabris C, Fornasiere E, et al. Vitamin D supplementation improves response to antiviral treatment for recurrent hepatitis C. Transpl Int 2011;24:43-50.

20. Abu-Mouch S, Fireman Z, Jarchovsky J, Zeina AR, Assy $\mathrm{N}$. Vitamin D supplementation improves sustained virologic response in chronic hepatitis $\mathrm{C}$ (genotype 1)-naive patients. World J Gastroenterol 2011;17:5184-5190.

21. Nimer A, Mouch A. Vitamin D improves viral response in hepatitis $C$ genotype 2-3 naïve patients. World J Gastroenterol 2012;18:800-805.

22. Yokoyama S, Takahashi S, Kawakami Y, et al. Effect of vitamin D supplementation on pegylated interferon/ ribavirin therapy for chronic hepatitis $C$ genotype $1 \mathrm{~b}$ : a randomized controlled trial. J Viral Hepat 2014;21:348-356.

23. Esmat G, El Raziky M, Elsharkawy A, et al. Impact of vitamin $\mathrm{D}$ supplementation on sustained virological response in chronic hepatitis C genotype 4 patients treated by pegylated interferon/ribavirin. J Interferon Cytokine Res 2015;35:49-54.

24. Kitson MT, Sarrazin C, Toniutto P, Eslick GD, Roberts SK. Vitamin D level and sustained virologic response to interferon-based antiviral therapy in chronic hepatitis C: a systematic review and meta-analysis. J Hepatol 2014;61:1247-1252.

25. Korean Association for the Study of the Liver (KASL). KASL clinical practice guidelines: management of hepatitis C. Clin Mol Hepatol 2014;20:89-136.

26. Stokes CS, Volmer DA, Grunhage F, Lammert F. Vitamin $\mathrm{D}$ in chronic liver disease. Liver Int 2013;33:338-352.

27. Itoh Y, Okanoue T, Ohnishi N, et al. Serum levels of soluble tumor necrosis factor receptors and effects of interferon therapy in patients with chronic hepatitis $\mathrm{C}$ virus infection. Am J Gastroenterol 1999;94:1332-1340.

28. Larrubia JR, Benito-Martinez S, Calvino M, Sanz-deVillalobos E, Parra-Cid T. Role of chemokines and their receptors in viral persistence and liver damage during chronic hepatitis C virus infection. World J Gastroenterol 2008;14:7149-7159.

29. Abramovitch S, Dahan-Bachar L, Sharvit E, et al. Vitamin D inhibits proliferation and profibrotic marker expression in hepatic stellate cells and decreases thioacetamide-induced liver fibrosis in rats. Gut 2011;60:17281737 .

30. Komolmit P, Kimtrakool S, Suksawatamnuay S, et al. Vi- 
tamin D supplementation improves serum markers associated with hepatic fibrogenesis in chronic hepatitis C patients: a randomized, double-blind, placebo-controlled study. Sci Rep 2017;7:8905.

31. Gal-Tanamy M, Bachmetov L, Ravid A, et al. Vitamin D: an innate antiviral agent suppressing hepatitis $\mathrm{C}$ virus in human hepatocytes. Hepatology 2011;54:1570-1579.

32. Grasso A, Malfatti F, De Leo P, et al. Insulin resistance predicts rapid virological response in non-diabetic, non-cirrhotic genotype $1 \mathrm{HCV}$ patients treated with peginterferon alpha-2b plus ribavirin. J Hepatol 2009;51:984-990.

33. Kim HB, Myung SK, Lee YJ, Park BJ; Korean Meta-Analysis (KORMA) Study Group. Efficacy of vitamin D supplementation in combination with conventional antiviral therapy in patients with chronic hepatitis $\mathrm{C}$ infection: a meta-analysis of randomised controlled trials. J Hum Nutr Diet 2018;31:168-177.

34. Lange CM, Bojunga J, Ramos-Lopez E, et al. Vitamin D deficiency and a CYP27B1-1260 promoter polymorphism are associated with chronic hepatitis $\mathrm{C}$ and poor response to interferon-alfa based therapy. J Hepatol 2011;54:887893.

35. Backstedt D, Pedersen M, Choi M, Seetharam A. 25-Vitamin D levels in chronic hepatitis $C$ infection: association with cirrhosis and sustained virologic response. Ann Gastroenterol 2017;30:344-348.

36. Lee SM, Jun DW, Cho YK, Jang KS. Vitamin D deficiency in non-alcoholic fatty liver disease: the chicken or the egg? Clin Nutr 2017;36:191-197. 